\title{
LECTORA Y TRANSGRESIÓN EN LA OBRA DE ALEJANDRO SAWA Y EDUARDO LÓPEZ BAGO
}

\author{
FEMALE READER AND TRANSGRESSION IN THE WORK BY ALEJANDRO \\ SAWA AND EDUARDO LÓPEZ BAGO
}

Pedro García Suárez

Universidad Complutense de Madrid

\section{RESUMEN:}

Este artículo se propone realizar un análisis sobre las heroínas lectoras que presentan tres de las novelas -La soltera, Crimen Legal y La mujer de todo el mundo- de los escritores naturalistas Eduardo López Bago y Alejandro Sawa. A través de su estudio se pretende mostrar la influencia del ejercicio lector en la configuración del género $\mathrm{y}$, al mismo tiempo, cómo su transformación influye en su posición como sujetos sociales.

\section{Palabras claves:}

Lectora, naturalismo radical, Sawa, López Bago.

\section{Abstract:}

I propose in this paper the analysis about the figure of the woman reader in the radical naturalism of Eduardo López Bago and Alejandro Sawa. Through the novels La soltera, Crimen Legal and La mujer de todo el mundo I perform a comprehensive study since they reflect a particular kind of eroticized reader barely admitted in the realist and naturalist Spanish novels.

\section{KEY WORD:}

Female reader, radical naturalism, Sawa, López Bago. 
Si el estudio de la figura de la mujer lectora en la novela realista y naturalista española resulta por sí mismo apasionante dadas las múltiples formas de interacción con un texto, especialmente sugerente se muestra un análisis acerca de las heroínas pertenecientes a la tendencia naturalista radical ${ }^{1}$. Este interés se fundamenta en las marcas propias que estas comparten y que, por esta razón, las hace únicas. Pese a que muestran ciertas características similares respecto al resto de heroínas lectoras tales como su falta de juicio a la hora de afrontar textos ficcionales o su deficiente formación, son sumamente originales respecto a su representación como mujeres fatales o a la manera en que interactúan con un tipo de texto normativo.

Comprendiendo que la institución religiosa se posicionó como un agente socia cuyo objetivo en relación a la mujer era la inoculación de una identidad femenina determinada y nombrada como ángel del hogar, parece complicado encontrar a un personaje capaz de asumir un modelo contrario como influencia del catolicismo. Es en este punto donde reside la mayor especificidad de las heroínas de López Bago y Sawa. Lectoras inocentes, diáfanas, que son pervertidas por la influencia de un catolicismo ideal.

Esta relación entre la religión y los personajes que proponemos para su análisis comienza desde que estos inician su etapa formativa. Aunque se propone la educación religiosa como un mecanismo dirigido a paliar los efectos ocasionados por una desenfrenada lectura ficcional, sin embargo, esta no parece provocar los efectos deseados.

Adentrándonos primero en las novelas de Alejandro Sawa, percibimos que concede una gran importancia a la educación, aunque no en el sentido tan amplio que se muestra en López Bago. Sus lectoras son víctimas de un romanticismo anacrónico debido a la influencia del catolicismo. Esta religión es entendida como un camino directo al terreno de lo ideal que, a su vez, conduce a la infamia. Por lo tanto, la relevancia de estas ideas en el período de formación femenino no solo impide la creación de un muro ante las afrentas de la ficción desenfrenada, sino que lo alientan. En este sentido, así se describe el supuesto fin de este tipo de educación en Luisa Galindo øprotagonista de la obra La

1 No ampliamos más información acerca del personaje de la mujer lectora en la novela realista naturalista española dado que ya ha sido abarcado por múltiples estudios. Entre otros, un bue ejemplo de estos es el trabajo realizado por O'Connor en 1985 “La mujer lectora y protagonista de la novela española del 1870", el artículo de Nora Catelli de 1995 "Buenos libros, malas lectoras: La enfermedad moral de las mujeres en las novelas del siglo XIX", la tesis doctoral de Acevedo-Loubriel en el año 2000 "Representaciones ambiguas: la lectora en la narrativa de Benito Pérez Galdós, Leopoldo Alas y Emilia Pardo Bazán”, el estudio de Samartín y Bastida en 2002 “La imagen de la mujer lectora en la segunda mitad del siglo XIX: La Ilustración Española y America y el Harper's Weekly" o el trabajo de Amelina Corre en 2006 "El siglo de las lectoras". Asimismo, dedico dos de mis trabajados académicos a este mismo tema: "Marcas «femeninas» en la imagen del hombre lector en la novela realista/naturalista española" y "La imagen de la mujer lectora en Armando Palacio Valdés". mujer de todo el mundoø: "Educada esa joven, esa niña, en los preceptos severos de una religión que mira más hacia lo alto que hacia abajo, enamorada del cielo, rechazaba todo cuanto pudiera distraerla de sus amores celestes" (Sawa, 1988: 129).

El idealismo conturba la racionalidad de la heroína. Las consecuencias esperadas no son posibles, dado que el sistema católico no es capaz de proporcionar a la futura mujer los conocimientos necesarios que le permitan aprender el código social femenino: “Tú que me llamabas loca en el colegio porque no sabía decía cuatro palabras serias, una después de otra... -Es que entonces el cielo azul entraba más amorosamente en mis pulmones que ahora: ¡ahora me ahogo, como si pudiera haber almas asmáticas!” (115).

Por lo tanto, esta lectora de folletines es conducida por el confesor hacia el amor -su verdadera naturaleza- que, cual Celestina, induce a Luisa hacia el matrimonio:

Pero llegó un día, en que la joven de que hablo, que había nacido para el amor que amaba sin saberlo, que tenía apetitos y deseos e ilusiones quizá más ardientes que los de otra cualquier mujer, por lo mismo que estaban más contenidos, oyó a su confesor $[\ldots]$ que le susurraba con emoción un nombre al oído [...] poniéndose al nivel de una inmunda Celestina, le hacía por encargo de ese nombre una verdadera declaración de amor, de amor sin límites, como el que ella deseaba y llevaba tempestuoso en el pecho. (129-130)

“Cómo dudar de la lealtad del sacerdote y del consejero?” (130). Por lo tanto, la educación católica es el factor clave que aleja a la heroína de Dios y la acerca al peligro romántico.

Sin embargo, en Rafaela ๑personaje de la novela Crimen Legalø no es únicamente su educación la que influye en su desarrollo, sino la formación católica recibida por un médico. Las consecuencias de la impregnación de este catolicismo en todos los ámbitos no se limitan a la interiorización del imaginario romántico. Las creencias religiosas de médico que la atiende en el primer parto provocan que llegue al borde de la muerte.

De este modo, descubrimos un poco más acerca de cómo es entendida la figura de la madre en esta religión. También en esta dimensión tan propiamente femenina percibimos una posición secundaria de la mujer respecto al hijo, incluso antes de nacer.

En la obra seleccionada de Eduardo López Bago encontramos una preocupación similar ante la influencia del idealismo católico. Sin embargo, su visión sobre la educación abarca un mayor análisis.

La soltera comienza con una larga descripción sobre la educación ofrecida en un colegio extranjero para niñas procedentes de familias aristócratas o del escalafón más alto de la burguesía. A través del análisis de la decoración que ostenta Le Petit Jesus se puede descubrir lo poco que allí importa el conocimiento: 
El piso de las niñas, o lo que es lo mismo, el principal, según que ya sabemos, resultaba una preciosidad. Las clases no tenian aspecto de tal, sino que parecian otros tantos gabinetes en lo que se podía suponer cualquier destino menos el de enseñanza, porque la instrucción andaba por allí como escondida en los cajones de mueblecitos de laca, como disimula da hasta el punto de no distinguirse objeto

alouno que la delatara por ninguna parte. (López Bago, 1886: 9; cursivas del texto)

En esta institución educativa, todas las alumnas poseen una pequeña biblioteca compuesta de textos de diversaíndole. Sin embargo, consideramos que esta información únicamente sirve para subrayar la deficiente formación ofrecida. Se proporcionan unos "conocimientos de adorno" (182) que consiguen pervertir y acabar con la inocencia de aquellas niñas: "cosa o persona que entrase o cayese bajo el poder de aquella individua habia de salir transformada a prodigio [...] de bueno en hipócrita, de verdadero en falso" (26). Este período formativo está dirigido a la conversión de sus alumnas en agentes sociales, es decir, a la asimilación del imaginario femenino para su posterior aplicación en sociedad. Este código queda resumido en el libro utilizado para enseñar que es escrito por la propia directora:

La clase de lectura y escritura. El texto que servía para la primera era un libro escrito por la mismísima Madame, y titulado nada menos que de esta manera: Vademecum de la perfecta señorita, y en el cual se detallaba cuanto se relaciona con el trato social, y estaban los más árduos problemas de éste, al decir de la que lo escribió. (10; cursivas del texto)

Es tal la pretensión constructora del libro que abarca tanto el rol como agente social como su actuación en el ámbito privado:

Dividíase en capítulos titulados, y cada capítulo trataba de una contingencia. Madame Desjarrets en su Vademecum cogía a la perfecta señorita por la mañana en el lecho, y ya no la soltaba hasta dejarla acostada otra vez por la noche al regresar del baile o del teatro. (10)

Sin embargo, se muestra como crítica al ser una acción no conducente al ideal sugerido: "Allí radicaban aquellas ideas erróneas de que Arturo [...] estaba tratando en su meditada y sentida epístola" (163).

Madame Desajarrets resultaba criminal suministrando a la fortaleza y robustez de tales sentimientos, en dosis pequeñas, pero diarias, el veneno de la hipocresia, y era la enseñanza, sin saberlo, el más importante factor de la malicia que sustituía poco a poco a la inocencia encantadora de la niñez y a lo picaresco de la pubertad. $(40)$

Únasele a esta hipocresía una exaltación de la sentimentalidad que impregna sus clases de escritura; y cuyos ejercicios se componen en la realización de cartas de amor.
En este plan de estudios la religión católica ostenta un protagonismo esencial. Esta queda caracterizada por su poder corruptor, cuya primera manifestación es su texto esencial: la Historia Sagrada.

Guarda la mujer muchos secretos para los hombres, guárdalos hasta para sus amantes, y entre ellos el mejor guardado es el secreto de su perversion. Empieza quizás en los colegios católicos por la lectura y estudio de la Historia Sagrada, porque la vaguedad que en el texto emplean los autores al tratar, por medio de simbolismos, tan ridículos como el de la manzana en la historia de Adán y Eva, los asuntos pornográficos, que más que en otra alguna abundan en la fabu y catolicismo, al tratar esto asi, excitan y avivan la curio (t) en proverbial en la mujer, y la imaginación se lanza a las hipótesis [...]. (43)

El despertar de la depravación sexual asimismo aparece como una causa del ejercicio confesor. La información que los directores espirituales ofrecen a las niñas es la principal causante de la inclinación hacia el deseo carnal.

En resumen, todo el dinero invertido en la educación de Rita en el extranjero no es más que un grave error que nuestra heroína tendrá que arrastrar durante toda su vida luchando siempre contra el sensualismo. Desde luego, aparece representada como un punto de partida deplorable para la lectura de novelas:

Puesto que a tan subidos honorarios, como los que se pagaban en la pensión dirigida por Madama Desjarrets, habínnla enviado sus padres al extranjero, donde de enseñanza (pour boire), la teoŕa y la práctica del vicio yor via de propina realizarlo con la frenética vehemencia [...]. (182; cursivas del texto)

Dado su bagaje, no nos sorprende el tipo de lectoras en que estas heroínas se han convertido. Unos personajes que acometen el ejercicio de manera fundamentalmente pasiva, usurpando inconscientemente aquellos contenidos reservados a la construcción de género denominada masculina.

Por esta razón, Luisa Galindo es directamente influenciada por la novela de folletín Además de comenzar a leerlas en el momento crucial de forjamiento de su posterior personalidad, observamos, a través de este personaje, la creencia de que este tipo de literatura conduce directamente a la depravación sexual en la mujer de acuerdo a los códigos de la época, ya que "los saberes definen los que sea la perversidad, lo marginado" (Zavala, 1993: 36)

Los indicios de desviación generados a raíz de estas lecturas se manifiestan ya desde el primer momento. El cambio fundamental es de perspectiva. Una transición que lleva a considerar al hombre como objeto deseable carnalmente. A su vez, este

2 Se puede observar la importancia que el autor otorga a la lectura en el poder que el texto tiene en su educación. Tanto el Vademecum como la Historia Sagrada son principales culpables de los errores de este proceso educativo.

Revista Internacional de Culturas y Literaturas, abril 2016 
viraje produce un cambio del concepto de matrimonio. Como expresa la marquesa de Zarzal, "Luisa ha ido al matrimonio, como otras mujeres van a la prostitución” (Sawa, 1988: 76). Un desplazamiento que se presenta como consecuencia del romanticismo anacrónico en que parece vivir la señorita de Galindo:

- ¿Ves, el romanticismo que efectos produce en algunas cabezas? [...]. -iYa esperaba esa palabra! ¡El romanticismo! - ¡Milagro que no me saludara Vd. con ella antes! - ¿Se llama romanticismo a todo lo que engrandece la condición humana? -Pues entonces, sí, -Llámeme Vd, romántica, señora, yo acepto la palabra con agradecimiento... (127)

Asimismo, como tantas otras, nuestra heroína interioriza el discurso y los ademanes de las protagonistas de sus lecturas: “-Voy a ensayar un resto de fuerza para contestarla a Vd. -Mire Vd., señora, casi el argumento de una novela al uso" (128).

La novela de folletín también es la principal responsable de la caída de Rafaela. Sin embargo, en la obra no encontramos un análisis en profundidad de los diferentes títulos o autores en los que se sumerge. Jiménez Morales (2008: 118) explica la tendencia de muchos autores a no aludir directamente a los libros o autores a los que se acercan por el hecho de no "comprometerse con unos escritores que, tal vez, hayan sido sus maestros o [...] hubiesen admirado personalmente". Sin embargo, nosotros consideramos que puede ser más una estrategia de estigmatización a un género y advertencia de su peligrosidad, elemento que también percibe esta investigadora al comentar que se focaliza más "en sus efectos y consecuencias morales, sociales o fisiológicas" (130).

Únicamente se profundiza en las consecuencias devastadoras de la construcción mental de la realidad a través de ella. Unas estructuras románticas que no son aplicables a su realidad y que, cuando se aplican, se produce la caída. En esta batalla contra el anacronismo de este tipo de textos, cobra especial relevancia el uso de los elementos sexuales usados en los autores escogidos pertenecientes al naturalismo radical.

Ricardo no tiene más que recurrir a las manidas frases de esos libros para acabar con su virginidad ${ }^{3}$. Una virginidad que, sin embargo, resulta el principal valor de una mujer en las obras que le heroína lee, una "metáfora de su integridad moral", un "signo externo de su valor" (Usandizaga, 1993: 32)

Esta distorsión romántica de la realidad va a acompañar a la heroína durante toda la obra. Incluso en la enfermedad, entre delirios, Rafaela hace memoria de una vida ficticia, sin acordarse de los acontecimientos reales. Sin embargo, la idealización

3 Es curioso que la heroína considera "yo no soy romántica" (59), demostrando así la poderosa acción que las lecturas tiene sobre ella.

4 Amplía Michelle Perrot (1993: 10): “La virginidad no se alaba por sí misma y por su valor religioso, sino como garantía de pureza, salvaguardia casi biológica del capital genético". también se mantiene en los períodos en que está sana: "Deliraba la loca con lo que, siendo cuerda, era su pensamiento latente" (Sawa, 2012: 99).

La novela también es la pieza clave para atender a Rita como lectora. Su introducción resulta muy temprana y en uno de los momentos más delicados de su vida: su infancia. En el momento en que debe estar forjándose una personalidad adecuada para su posterior inclusión en la sociedad a través del afamado colegio, aparecen estas lecturas en sus manos.

Desde el instante en que estas hacen su aparición, se impone un modo identificativo de leer en las alumnas. Asimismo, volvemos a encontrar una clasificación de estas respecto al grado de peligrosidad que portan. No se considera adecuada la novela en general, pero hay ciertas obras extremadamente censurables en particular. Curiosamente, las obras señaladas como prohibidas son aquellas tan temidas por muchos de los escritores realistas y naturalistas: las traducciones de obras foráneas.

Esta clasificación es nuevamente manifestada y, al mismo tiempo, explicada en el Episodio Nacional galdosiano La estafeta romántica (1994: 27-28). Doña María Tirgo considera que la afición de Demetria a los libros es gravemente perjudicial por el daño que pueden hacer: "Ahora la ves agrandando cada día los ratitos perdidos, o sea, los que consagra a este entretenimiento de los libros, que me parece son prohibidos"; un perjuicio causado por la afición específica de la heroína por la literatura "sentimental y de lloriqueos, tristezas y desastres, pues no sólo anda resobando al tal Uberte o Güerter, sino también a otros libros y novelas de amores contrariados".

De ellas, la primera consecuencia va a ser la extrapolación de las cualidades del hombre ideal, es decir, la idealización del futuro amado. Como en la mayor parte de las lectoras, observamos una preconfiguración romántica y literaria que se construye y, lo más importante, que predetermina sus expectativas frente al futuro.

Esta influencia de las lecturas en su concepción del amor es doble ${ }^{5}$. Además de la literaturización del hombre ideal, Rita desafía al patriarcalismo adoptando un concepto del amor romántico y carnal, las dos acepciones más censuradas en este imaginario decimonónico:

Y combinada la lectura de novelas con las confidencias del confesionario, dividióse, con respecto al amor, en dos pareceres la opinión de las pensionistas del Petit Jesus dos conceptos que puedo llamar romántico y realista respectivamente. Ruta y dos conceptos que puedo llamar romántico y realista respectivamente. Ruta y
Consuelo adoptaron, según se sospecha, un término medio, tomando lo mejor de cada sistema. (López Bago, 1886: 65)

5 En este caso, no solo actúa el ejercicio lector en esta asunción de patrones, pero sí que se resalta como uno de los factores más importantes. La lectura termina de moldear lo adquirido a través del confesionario y el colegio.

I Culturas y Literaturas, abril 2016 
Las consecuencias de esta lectura se hacen patentes cuando conoce a Arturo. Desde el primer acercamiento, encontramos elementos subversivos. Por un lado, la heroína intenta seducir a un hombre desconocido, tomando una iniciativa que no le estaba permitida ${ }^{6}$. Incluso su nombre es novelesco: “Arturo, ¡nombre de novela!” (101).

Ella seguía mirándole con insistencia, y él, al verse descubierto, sonrió [...]. La inglesita, a pesar de su tez morena y de sus ojos y cabellos negros, era una española muy formal en sus gustos, muy adelantada en sus predilecciones, y sobre todo muy valiente, temeraria: porque ya lo he dicho, aquel hombre resultaba un peligro, uno de esos peligros de pasión que las mujeres presienten y conocen y de los que un

del sexo. Rita se acercaba. (97; cursivas del texto)

Es necesario señalar que cualquier muestra de autonomía personal o actitud activa resulta totalmente contraria a las características que se le presuponen a la lectora por e simple hecho de ser mujer y, por otro lado, opuestas a las deseadas en esta mujer ideal vehículo de la regeneración moral y social del país.

Sin apenas conocerle, la lectora cree saber quién es a través de los héroes de sus lecturas. Rita convierte a un hombre desconocido en la encarnación de sus expectativas ${ }^{7}$. Esta tendencia romántica se agudiza por la manera en que se fragua su relación: "para contribuir poderosamente a la ilusión, estaba la índole misma de sus amores. Miradas desde lejos, cartas y sonrisas" (López Bago, 1886: 107).

Finalmente, el romanticismo es aplastado por la realidad, representado en la crueldad de Morán. La violación deja a Rita provista únicamente de su lado más perverso y carnal: "Para eso había servido el acto brutal de Morán. Para acabar con todos los pensamientos de amor y quitar estorbos. Un matrimonio de conveniencia. Un hombre que sirviera para el caso. Un tonto o un sin vergüenza" (López Bago, 1886: 229).

Además de la acepción romántica, la heroína también entiende esta relación desde el lado más realista. Como podemos observar, el instinto sexual se despierta en Rita desde el primer beso con Arturo:

El médico rodeó con su brazo el talle de la virgen, la atrajo hacia sí dulcemente, se inclinó hacia ella y buscó su boca. El estallido del beso sonó bajo los árboles. Rita cerró los ojos, vaciló un momento y tuvo que apoyarse después de la caricia en el brazo del hombre porque sintió como un vahído, por la profunda impresión recibida. No hubo resistencia, ni palabras de reproche. Rita no gustaba de fingimientos. (128)

6 Toma, además, "cierto aire de resolución hasta entonces no manifestado" (98)

7 Por lo tanto, Rita se suma a todas aquellas lectoras que preconfiguran sus expectativas sobre el hombre a través de sus lecturas.
Este despertar sexual se produceenla pubertad y ya va a acompañar permanentemente a la lectora. Incluso llega a iniciarse en la prostitución. En este proceso tiene tal peso la religión católica, que incluso va a llegar a excitarse ante su imaginería: “iMás de una vez por estas representaciones e imágenes de talla, llegó a sentirse excitada también, y creyó que la religión católica hubiese debido suprimir tal indecencia!" (177-178).

En conclusión, encontramos en Rita a la lectora erótica, que responde a que "la mujer es imaginada como devoradora de libros y, también, de hombres" (Blanco, 1998: 16) Aquella cuyas lecturas le inducen a adentrarse en un terreno prohibido para la mujer decente: el deseo sensual. Como expone Iris M. Zavala (1993: 36), a partir de la segunda mitad del siglo XIX “las prácticas sexuales se convierten en discursos" y, de esta manera, "El discurso sobre el sexo se convierte en regulador de comportamientos". Por otro lado, esta heroína adolece de una doble desviación, al tener en cuenta la asimilación de los patrones románticos de esos libros.

Es el mismo caso que el de su madre. La novela va a estar continuamente asociada al erotismo de Mariquita. Como hemos podido observar en Rita, esta lectura provoca la interiorización del ideal romántico, resultando así la enfermedad:

Arriba, en el armario de cristales (porque no era una librería de última moda), vio las obras de Paul de Kock, traducidas; las de Dumas, hijo; las de Alarcón, La Pródiga y El Escándalo, únicas españolas que gustaban a la señora de López; novelas, muchas novelas, La Moda Elegante encuadernada por colecciones de año, algunos tomos de La Gaceta, y entre Paul de Kock y Alarcón dos tomitos, cuyos títulos, según rezaba el tomo, eran éstos: La Condesita, La Chula. Además un ejemplar del Código penal vigente, Año Cristiano en dos volúmenes y el Diccionario tauromaquico de Sánchez de Neira ${ }^{8}$ (López Bago, 1886: 89)

Este romanticismo conduce a Mariquita a la búsqueda incesante de un ideal que no existe. La frustración resultante de esta extrapolación ficcional convierte a la lectora en la mujer adúltera viciosa, fría, malvada que, en un grado más profundo de análisis, constituye una herramienta subversiva en la sociedad patriarcal: "Pedía tu madre a la vida real purezas que la realidad no tiene; al hombre, cariño tan extraordinario, que sólo se conoce por idealizaciones de la novela" (147).

Es decir, la heroína que ejerce este tipo de lectura se muestra siempre subversiva, independientemente del tipo de texto al que se acerque. Voluntaria o involuntariamente,

8 Respecto a las obras citadas de Alarcón, resaltamos la importancia de los elementos románticos en estas. Como apunta Ferreras (2010: 222), El escándalo (1875) "se sitúa a medio camino entre un romanticismo tardío, y ya muy idealizado, y un dualismo prerrealista que no tiene porvenir" y La pródiga (1882) cuenta con "la figura romántica de la protagonista". Por otro lado, La Condesita, memorias de una doncella (1870) y La Chula (1870) son dos novelas naturalistas pertenecientes al escritor Francisco de Sales Mayo. Sorprende entonces el gran abanico de lecturas de nuestra protagonista que comprende desde el Romanticismo de folletín de Paul de Kock hasta el naturalismo de Sales Mayo. 
su disposición hacia el texto conduce al personaje a sobrepasar los límites genéricos establecidos. Consideramos que Alejandro Sawa y Eduardo López Bago son los mejores exponentes de esta visión que asocia directamente la ficción romántica al deseo carnal. En su obra, las mujeres son directamente conducidas a la lujuria a través del terreno de lo ideal y predestinadas, por ello, a un final terrible.

Del mismo modo en que estos personajes se posicionan frente a un tipo de texto ficcional, acometen el ejercicio lector de cualquier obra de carácter religioso. Una parte de la culpabilidad por su comportamiento reside en la idealidad que desprenden estas obras y, como consecuencia, conducen a la inmoralidad y a la degradación. La novedad de las heroínas de López Bago y Sawa reside en la exención de toda responsabilidad personal de ellas, recayendo así todo el peso de la infamia en el mismo libro y, por lo tanto, otorgando una pasividad lectora muy lejana a otro tipo de lectoras pertenecientes al realismo y al naturalismo. El texto se muestra superior a la capacidad de las heroínas propuestas.

Por lo tanto, uno de los elementos comunes en las obras propuestas de estos autores es la concepción del texto religioso católico como una lectura que conduce inevitablemente a la lujuria, que corrompe en vez de edificar.

En este sentido, una de las escenas más explícitas la encontramos en Crimen Legal. El libro base del catolicismo adquiere el principal protagonismo en la pérdida de esa virginidad tan alabada de Rafaela:

Se habían aproximado el uno al otro instintivamente, enardecidos y excitados por las palabras del libro de Dios, palabras ardientes que expresan el amor sensual, el amor de la carne, y que sonaban en el oído de Rafaela con la misma armonía que una canción de amores sentida y apasionada, de esas que brotan más bien del corazón que de los labios. (Sawa, 2012: 64)

La Biblia aparece reflejada como un alcahuete, incitador consciente del deseo carnal entre la pareja: "La Biblia, el libro de Dios, fue el galeoto" (65). Incluso se nos ofrece información acerca del pasaje concreto que es capaz de suscitar tan desmesurada lujuria:

Es inconcebible que Ricardo, para vencer las repugnancias de la virginidad al contacto carnal para vencer las resistencias de Rafaela, apele a la lectura en voz alta del Cantar de los Cantares de Salomón [. . ] porque la Biblin es uno de los liboz que más excitan el sensualismo, y el Cantar de los Cantares sobre manera [...]. (230)

Encontramos entonces una percepción del texto sagrado semejante al de una novela Es decir, asistimos a la comprensión de ambos como textos peligrosos, susceptibles de profanar la castidad de una virgen, de llevarla a la perdición: “iBasura de lo ideal! ¡Un montón de basura!" (61). Esta idealidad que rezuma del libro es entendida como una droga, capaz de anular o modificar la naturaleza del que lo toma: “¡Esa basura desprende emanaciones que lesionan a la imaginación con la hipocresía de un veneno agradable, del haschisch o del ajenjo!" (61; cursivas del texto).

Al igual que Rafaela, Luisa Galindo se convierte en una presa más de este idealismo alejado de la realidad terrenal que empapa las lecturas católicas:

Luisa Galindo pensaba ahora que quizá se hacía preciso ser un poco canalla para merecer el amor de ese Dios hermoso como un sueño de ventura y posado en una nubecilla celeste, que le habían mostrado en las estúpidas enseñanzas de Le Sacré Coeur como síntesis hecha realidad del amor sumo, del bien sumo... de la eterna justicia. (Sawa, 1988: 112-113)

Esta actividad lectora de nuestras heroínas repercute directamente sobre su posición como sujetos sociales. Las modificaciones que acontecen en su personalidad a raíz de las lecturas que hemos expuesto conllevan catastróficas consecuencias, al ser relegadas a los márgenes de la sociedad.

Dada la poderosa relación de Luisa con su instinto sexual, es irremediablemente conducida a su posterior desengaño. El exaltado romanticismo provoca que consienta en la celebración de un matrimonio de conveniencia, que aparece como castigo a sus expectativas.

La no conformación con la privación de la actividad sexual pidiendo, por ello el divorcio, provoca la caída total de la heroína. Arruinada y sin separarse de él definitivamente. Recuérdese a Ana Karenina.

Su lascivia es tan intensa que comete dos graves alteraciones en el orden imperante. Además de la inmoralidad de su pensamiento, tan frecuentemente vigilado y censurado en la mujer, el personaje es penalizado por buscar en el matrimonio la satisfacción del deseo carnal. La heroína acude a la unión conyugal "en busca de placeres, buscando el hartazgo" (Sawa, 1988: 76).

Otro tipo de castigo que proviene de la sexualidad incontrolada se manifiesta en Rafaela que, debido al deseo carnal, se ve abocada a su destrucción. Aun sabiendo que un segundo embarazo supondría una muerte segura, la heroína suplica a Ricardo que la penetre:

Apretaba con ansia las manos de su marido, y le pedía con voz entrecortada, que parecía salir de lo más hondo de sus entrañas, cosas cuya concesión él negaba, con terquedad que constituia un nuevo incentivo para los furores genesicos de aquella especie de viuda que estaba casada [...]. Eso es lo que quería Ricardo; que partiera la iniciativa de su mujer; que fuera ella la que se le ofreciera. Así, evitaba responsabilidades para su conciencia. (Sawa, 2012: 170-171) 
Así, encontramos a la mujer lujuriosa, fuertemente unida a sus instintos. Únicamente consigue distanciarse de su objetivo cuando está enferma, casi al borde de la muerte. Sin embargo, no encontramos una culpabilidad directa de la lectora. No se enjuicia ni se percibe que posea una naturaleza frívola o maliciosa. Esta es la causa de la segunda manera en que Rafaela es percibida: como mártir. Una víctima de sus circunstancias, de sus novelas y del catolicismo que influye en todos los ámbitos: “Una tarde, Ricardo se levantó de la mesa después de comer, a la hora de costumbre; se vistió, como de ordinario, para salir a la calle; besó a la mártir en la frente, y salió de su casa tatareando un aire canallesco de Los Mosqueteros grises" (113).

Estos dos elementos repercuten en ella de un mismo modo: a través de la idealización inducen a la heroína a la depravación sexual y a la perspectiva de la vida desde una óptica romántica. Todo es ello es acentuado por la errónea educación recibida en el colegio. Y, de esta manera, Rafaela es presa de "los sueños de amor que conturbaron su organismo de virgen" (101).

Asimismo, encontramos a la mujer adúltera en López Bago. Mariquita es vilipendiada por el entorno de su marido. Observemos en el texto cómo incluso pierde su nombre en favor del calificativo de "adúltera" o "loca":

[...] esta adúltera era, después de todo, mejor, mucho mejor que los complacientes y lujuriosos consejeros de la corona, instrumentos conscientes de tales hazañas; mejor que el bueno y el infeliz del Sr. De López, a quien todos compadecín, por estar casado con una loca [...]. (López Bago, 1886: 16; cursivas del texto)

También es la mujer lujo, tan temida en la obra de Galdós. Es, por lo tanto, una heroína totalmente construida en un polo negativo, debido a que parece no poseer ninguna cualidad positiva. A Mariquita no la respetan sus clientes. Llega incluso a recibir una bofetada por parte de su hija. Ni siquiera permanece intacto el sentimiento más propiamente femenino: la maternidad.

Vista la percepción que se cierne en estas obras acerca de la lectura de carácter ficcional y religioso, no nos sorprende encontrar que el ejercicio lector se presente con un como una dimensión a esconder. De esta manera, las novelas llegan al colegio en el que se educa Rita como si se tratase de una mercancía peligrosa: "Como si hubieran caído del cielo, y venido por el aire (pues nadie supo quién las trajo), llegaron a la Pensión novelas" (López Bago, 1886: 64). Como Ana Ozores, Rita "había leído a hurtadillas una porción de libros" (75). Curiosamente, también Luisa Galindo accede a la novela de folletín a través de "una amiga suya del colegio, la señorita de Villodas" (Sawa, 1988: 61), y entonces podemos comprobar que, pese a la demonización de estos textos, circulaban incluso entre los colegios femeninos de la época.
El ejercicio lector es tan importante en las novelas que analizamos en relación al desarrollo de las heroínas que incluso consiguen modificar los espacios que se presentan. Este no solo aparece delimitado por la elección de las heroínas, sino que se transforma en función del carácter de la conexión establecida con el libro. Toda lectora relacionada con el deseo sensual asumido a través de las novelas parece empapar de esta sensación cualquier lugar que habite o en el que deposite sus lecturas.

El caso de Mariquita es la mejor herramienta para comprender las connotaciones que la novela tiene respecto a la lectora al averiguar el lugar donde decide colocar sus libros. Además de situarlos en el mismo espacio en que recibe a sus clientes, aparecen en una librería de dos cuerpos como un elemento más de depravación. Existe un gusto en la época por el uso de este tipo de mobiliario como elemento decorativo: "Los «armarios librería» o los «estantes para libros» eran muebles tan habituales en las viviendas como las cómodas o las sillas de Vitoria" (Martínez Martín, 1991: 83). Como en este caso, incluso pueden ser compartidos con otros objetos habituales "como ropa y loza". Asimismo, el hecho de que aparezcan colocados en una librería también nos ofrece información acerca de la clase social en que se inserta el personaje, y es que “en la configuración de los espacios domésticos de las élites [...] tuvo una entidad propia y autónoma del resto de las estancias la biblioteca, a diferencia de los libros de las clases medias alojados en librerías" (Martínez Martín, 2001: 465; cursivas del texto). En ella, se presentan al mismo nivel que el alcohol que utiliza para embriagarse con los hombres a los que recibe.

En Crimen legal también se sitúa la novela en un espacio asignado a la lujuria: un prostíbulo. Aunque no se nos especifica el título de la obra, sí que sabemos que su argumento gira en torno a la aventura y al amor. Por lo tanto, ya obtenemos una mayor información acerca del tipo de texto que puede conducir a la perversión: “En el centro un gran velador de mármol blanco, y sobre él una novela, la última que publicó $E l$ Imparcial -una novela de mucho enredo y de muchos amores; castos, por supuesto-" (Sawa, 2012: 121)

No conformándose con ello, se subraya que la lectura es uno de los pasatiempos de una prostituta, resaltándose, a su vez, el modo y el lugar-el gabinete, de nuevo- en que esta actividad es realizada: "Noemí pasaba sus extraños ratos de soledad bostezando o leyendo" (144)

Son entonces las heroínas presentadas de López Bago y Sawa todo un ejemplo de originalidad como lectoras. Pese a que manifiestan una forma similar de posicionamiento frente a la ficción en comparación con otras lectoras pertenecientes al realismo y al naturalismo, su relación con la religión es diametralmente diferente. No es que simplemente se aproximen a un texto religioso realizando una lectura transversal sino que es el propio texto el que se presenta como propicio a ser interpretado y 
asumido de una manera inversa a una intención inicial. Nos encontramos frente a una forma de transgresión no voluntaria por parte del personaje. Asimismo, llama la atención la focalización de las consecuencias de la lectura desmedida y sin filtro sobre una sexualidad igualmente descontrolada. Una sexualidad que aparece representada como clave en relación a la mujer para ser exiliada a los márgenes. Debido al efecto desviante de la lectura, desde el punto de vista de Bourdieu (2000: 41-42), el sujeto sexuado no ha realizado el aprendizaje corporal adecuado utilizado como herramienta de asimilación de las normas sociales. En una línea de pensamiento foucaultiana, la mujer fatal, con instinto carnal, es marcada por el resto del entorno y conducida, por ello, a una periferia en lo que no existe una vuelta atrás. Incluso pese a que, desde el punto de vista del narrador, son eximidas de toda culpa. Es decir, no existe ningún tipo de voluntariedad en esta transformación personal, que convierte a inocentes niñas en mujeres depravadas.

\section{REFERENCIAS BIBLIOGRÁFICAS}

Blanco, A., "Escritora, feminidad y escritura en la España de medio siglo", en Iris M. Zavala (coord.), Breve historia feminista de la literatura española (en lengua castellana), vol. V: La literatura escrita por mujer: del s. XIX a la actualidad, Barcelona, Anthropos, 1998, pp. 9-38.

Bourdieu, P., La dominación masculina. 2aㅡ ed., Barcelona, Anagrama, 2000.

Charnon-Deutsch, L., Gender and representation: women in Spanish realist fiction, Amsterdam, Philadelphia: John Benjamins Publishing Company, 1990.

Clarín, L. Alas, "Carta II a José Quevedo”, en Francisco García Sarriá, Clarín o la herejía amorosa, Madrid, Gredos, 1975, pp. 249-253

Díaz Tejera, A., "El género en griego clásico: descripción sincrónica y explicación diacrónica”, Revista Española de Lingüística, 11 (1981), pp. 13-31.

Ferreras, J. Ignacio, La novela en España: historia, estudios y ensayos, t. III: Siglo XIX, Madrid, La Biblioteca del Laberinto, 2010.

Jiménez Morales, M. Isabel, "Antifemenismo y sátira en la lectora española del siglo XIX", en Pura Fernández y Marie-Linda Ortega (ed. y dir.), La mujer de letras o la letraherida: discursos y representaciones sobre la mujer escritora en el siglo XIX, Madrid, Consejo Superior de Investigaciones Científicas, 2008, pp. 115-136.

López Bago, Eduardo, La soltera (segunda parte de La señora de López): novela social, Madrid, Juan Muñoz y Compañía, 1886.

Martínez Martín, Jesús A., Lectura y lectores en el Madrid del siglo XIX, Madrid, Consejo Superio de Investigaciones Científicas, 1991.

Martínez Martín, Jesús A. (dir.), Historia de la edición en España (1836-1936), Madrid, Marcial Pons, Historia, 2001.
Pérez Galdós, B., La estafeta romántica. Madrid, Información e Historia. 1994.

Perrot, M., "Historia, género y vida privada", en Pilar Folguera (comp.), Otras visiones de España, 1ํㅡㄹ. ed., Madrid, Pablo Iglesias, 1993, pp. 1-26.

Sawa, A., La mujer de todo el mundo, Madrid, Móreno-Avila, 1988.

----, Crimen legal, edición, introducción y notas de Amelina Correa, Sevilla, Renacimiento, 2012.

Usandizaga, A., Amor y literatura: la búsqueda literaria de la identidad femenina, $1^{\underline{a}}$ ed., Barcelona, PPU, 1993.

Zavala, Iris M., “Las formas y funciones de una teoría crítica feminista. Feminismo dialógico", en Myriam Díaz-Diocaret e Iris M. Zavala (coords.), Breve historia feminista de la literatura española (en lengua castellana), vol. I: Teoría feminista: discursos y diferencia, pról. Iris M. Zavala, Barcelona, Anthropos; San Juan, Puerto Rico, Editorial de la Universidad de Puerto Rico, 1993, pp. 27-76. 